\title{
Effect of Tepid Sponging Versus Warm Sponging on Body Temperature and Comfort among Under-Five Children with Pyrexia: Correspondence
}

\author{
Prateek Kumar Panda $^{1} \cdot$ Indar Kumar Sharawat $^{1}$ (D)
}

Received: 30 October 2021 / Accepted: 18 January 2022 / Published online: 16 February 2022

c) Dr. K C Chaudhuri Foundation 2022

To the Editor: We read the recent article by Jose et al. [1]. They have demonstrated that both tepid sponging and warm sponging were equally effective in reducing body temperature in children with pyrexia.

They did not mention whether oral or intravenous paracetamol was also administered along with sponging. They have mentioned that tepid sponging and paracetamol together is the best modality for early management of fever [2]; hence, withholding paracetamol in a child with fever, apart from raising ethical concern, may also increase chances of complications [3]. In such a case, the authors need to mention how many children in each group subsequently required oral or intravenous antipyretic. If the investigators have also administered paracetamol simultaneously with warm or tepid sponging, they need to mention how they differentiated whether the temperature reduction was primarily due to sponging.

Secondly, the authors did not mention whether baseline demographic and clinical characteristics like age and gender distribution, baseline temperature, cause of fever, etc. were comparable between both groups, as skewed distribution of these variables is likely to affect the results of statistical analysis for the primary outcome. The authors have mentioned that the mean comfort level during warm sponging (69.97) is higher than tepid sponging (37.05). The obtained $t$-value $(-42.94)$ is statistically significant $(p<0.001)$, but they did not mention the objective scale or measuring instrument used like COMFORT scale or specifically-designed scale/ instrument for this purpose, which accurately documented comfort level in young children [4]. Moreover, the authors did not mention whether these children had any associated symptoms like headache, pain abdomen, or respiratory distress, as the presence of these associated symptoms might have affected the comfort level of young children.

The authors have also not mentioned how they quality assured regarding the subjective variation in caregivers providing warm and tepid sponging and whether any prior teaching by video demonstration or other methods were attempted in them.

\section{Declarations}

Conflict of Interest None.

\section{References}

1. Jose J, K M, A SSN, Jose JP, Baby G. Effect of tepid sponging versus warm sponging on body temperature and comfort among under-five children with pyrexia. Indian J Pediatr. 2021. https:// doi.org/10.1007/s12098-021-03985-1.

2. Plaisance KI, Mackowiak PA. Antipyretic therapy: physiologic rationale, diagnostic implications, and clinical consequences. Arch Intern Med. 2000;160:449-56.

3. Sharawat IK, Singh J, Dawman L, Singh A. Evaluation of risk factors associated with first episode febrile seizure. J Clin Diagn Res. 2016;10:SC10-3.

4. Carnevale FA, Razack S. An item analysis of the COMFORT scale in a pediatric intensive care unit. Pediatr Crit Care Med. 2002;3:177-80.

Publisher's Note Springer Nature remains neutral with regard to jurisdictional claims in published maps and institutional affiliations.

Indar Kumar Sharawat

sherawatdrindar@gmail.com

1 Pediatric Neurology Division, Department of Pediatrics, All India Institute of Medical Sciences, Rishikesh,

Uttarakhand 249203, India 